DOI 10.37882/2500-3682.2020.10.16

\title{
ТРАНСФОРМАЦИЯ СУЩНОСТИ ПОЛИТИКО-ПРАВОВЫХ ИНСТИТУТОВ В КОНТЕКСТЕ ПОСТСОВРЕМЕННОСТИ
}

\section{POLITICAL AND LEGAL INSTITUTIONS ESSENCE TRANSFORMATION IN THE POSTMODERNITY CONTEXT}

\section{N. Ravochkin}

Summary: In this work, the author makes an attempt at a sociophilosophical analysis of the main vectors of essential transformations of political and legal institutions in the postmodern world. The theoretical and methodological foundations were the concepts of M. Foucault, J. Agamben and M. de Certeau. Theories of everyday life and biopolitics are analyzed. The influence of each direction is noted. In accordance with the logic of the work, the influence of the considered grounds on the transformation of political and legal institutions is determined. The necessary explanations and clarifications are given. In conclusion, the author defines summarizes the work.

Keywords: political and legal institutions, transformation, biopolitics, everyday life, power, society, Postmodernity.

\author{
Равочкин Никита Николаевич \\ К.ф.н., дочент, Кузбасская государственная \\ сельскохозяйственная академия; Кузбасский \\ государственный технический университет \\ имени Т. Ф. Горбачева \\ nickravochkin@mail.ru
}

Аннотация: В настоящей работе автор предпринимает попытку социально-философского анализа основных векторов сущностных трансформаций политико-правовых институтов в постсовременном мире. Теоретико-методологическими основаниями послужили концепции М. Фуко, Дж. Агамбена и М. де Серто. Проанализированы теории повседневности и биополитики. Отмечено влияние каждого направления. В соответствии с логикой работы определено влияние рассматриваемых оснований на трансформацию политико-правовых институтов. Даются необходимые пояснения и уточнения. В заключение автор определяет подводит итоги работы.

Ключевые слова: политико-правовые институты, трансформация, биополитика, повседневность, власть, общество, Постсовременность.

него поведения (принуждения со стороны) в различные области не-политических форм принуждения [2]. На этом основании власть и соответствующие институты становятся средствами биологического принуждения.

Помимо этого, в данной концепции человек рассматривается как предмет самовоспроизводства. Здесь мы регистрируем отголоски марксистской традиции, проявляющиеся в форме практической реализации и трансформации идеи о политической экономии. В рамках данной идеи тело человека становится предметом, которое необходимо постоянно воспроизводить. Именно по этой причине М. Фуко и Дж. Агамбен, как и многие другие теоретики-приверженцы концепции биополитики, стремились анализировать формы и способы реализации биологического контроля над человеком через медицинские учреждения, ритуальные и другие услуги.

В частности, А.И. Желнин отмечает, что для Хардта и Негри «субъектом биовласти является глобальный капитал, ищущий все новые пути извлечения прибыли и далеко не всегда имеющий политическое (государственное или надгосударстенное) «лицо». Биовласть - это по своей природе экономическая власть, целью которой является явная или скрытая эксплуатация в рамках производства, понимаемого предельно широко как производство жизни, «жизненного мира» в его целокупности» [1, 322]. Выходит, практическое применение концепции 
биополитики состоит в том, что человек воспринимается в качестве биокапитала, содержание которого можно усмотреть посредством взгляда на его используемые значимые свойства. При этом используются методы и приемы, позволяющие задействовать не социальные свойства человека, поскольку это достаточно затратно с точки зрения соотношения вкладываемых ресурсов и получаемого результата, но биологические стороны. Кроме того, приемы реализации последней куда менее затратны, но в то же время они приносят несоразмерно более высокий властный результат. Сущность биокапитала заключается в том, что при сохранении иллюзии внешних свойств свободы и равенства людей, последняя служит интересам власть имущих, т.е. интересам накопления капитала, главным методом которого становится максимальная оптимизация людских ресурсов и формирование ее полезности для рыночных механизмов. Так получает свое развитие идея Большого Брата, существование которого скрыто для обыденного мышления от непосредственного восприятия. Любопытно, но даже критики биополитики признают, что такое понимание биовласти является феноменом современного понимания трансформаций политический в целом и властных - в частности отношений. Таким образом, М. Фуко и Дж. Агамбен указали на тенденции изменений политических отношений именно в современном мировом обществе.

В рамках концепции биополитики и биовласти существенными становится основания рассматриваемых институтов, поскольку отныне применяются не внешние формы принуждения (силовые методы и способы заставить человека выполнить желаемые действия), но внутренние, тесно связанные с психологическими приемами. Так, можно утверждать, что одним из оснований биополитической концепции политико-правовых институтов становится система французского психоаналитика и постструктуралиста Жака Лакана, в которой мыслитель выделяет идею так называемого «Большого Другого».

В лакановской концепции данный интеллектуальный конструкт реализуется в форме трансформации и актуализации ставших традиционными для гегеловской диалектики отношений рабства и господства. Французский мыслитель переводит эту диалектику в плоскость бессознательного, показывая, что основные принципы отношений между двумя противоположностями сохраняются не только на внешнем, но и на внутреннем уровне. Центральным здесь становится тезис о расхождении реального субъекта, являющимся адресатом сознательного дискурса и Другого как реципиента бессознательной речи. Через аналитику отношений между двумя данными началами Лакан констатирует моменты диалектики борьбы за признание. Появление этих двух структурных элементов объясняется Лаканом через «стадию зеркала», когда сознание становится результатом первоначального отчуждения. Структура «Я» формируется в про- цессе присвоения внешнего образа в качестве гештальта как модели правильного поведения, которое свойственно для вполне конкретного человека [8]. Такой гештальт становится основанием синтеза разрозненных психических переживаний: человек отождествляет себя с объектом, который реализует функцию воображения. Это значит, что мы отождествляем себя с тем, что воспринимаем в качестве приятного.

Как результат из вышеописанного - расщепление на реального оппонента, с которым мы себя соотносим, и, соответственно, оппонента бессознательного, к которому мы делаем запрос в логике «являйся похожим на вполне конкретный и приятный мне образ». Подобным образом человек признает нехватку идеального, того желанного образа, на который он хочет быть похож. По итогу такое желание формируется в форме прибавочного смысла, при помощи которого мы можем организовать полноту бытия. Можно провести еще одну аналогию и отметить, что в рамках лакановского психоанализа и предлагаемой им «стадии зеркала» реализуется идея К. Маркса об эксплуатации угнетенного класса синтезом экономических и психологических средств. То есть используется совсем не-телесное принуждение, а скорее навыки властных структур создавать привлекательные образы, которые каждый эксплуатируемый раб стремится сделать «своими», не осознавая при этом, что желанные образы никогда не будут таковыми. Однако понимание этих механизмов человеческих устремлений может быть использовано для подчинения человека. Концепция микро-макро-сверхвласти М. Фуко предполагает тенденцию трансформации методов исполнения властных полномочий. Ее суть заключается в том, какие именно ресурсы используются для контроля над человеком. Микровласть суверена направлена на конкретного человека со всеми его правами как то, что приносит доход в казну. Такая власть затратна, поскольку каждый отдельный человек требует больших ресурсов принуждения во всех ветвях власти. Принуждается человек как социальное существо с помощью преодоления его социальных свойств и навязывание ему, человеку, новых, выгодных для властных структур, социальных свойств.

Макровласть в форме паноптикума [9] оказывается менее затратной, поскольку принуждается отдельный человек, выполняющий функцию без обладания гражданскими и естественными правами. Люди становятся телами, обладающими функционалом, обращение к использованию которого допускается в самых разнообразных формах. В таком случае человек уже изначально подчиняется заранее заданным функциям, поскольку теперь он принимает это положение дел в качестве «нормального». Данное принятие основывается на том, что человек осознает невозможность его принятия в общество без выполнения определенных социальных функций. Нормальность отождествляется с набором 
функций, который определяется и задается принципами властных структур. В целом, такая логика облегчает возможность функционирования политико-правовых институтов, да еще и при условии меньших затрат. Макровласть в форме биовласти направлена на толпу [4]. Осуществляется контроль за биологическими процессами, свойственными всем людям как живым существам. Рождение, смерть, воспроизводство, болезнь - все они становятся ресурсами власти. Использование желаний и потребностей людей (психологических и биологических) дает возможность переложить ответственность за выполнение необходимых функций на самих людей, которые автоматически признают необходимость «правильных» действий в форме «заботы о себе».

На основании выявленных ресурсов М. Фуко утверждает, что властные структуры формируют желательный образ человека, который формируется с помощью психологически привлекательного образа. Такой способ властвования требует минимальных ресурсов принуждения. В качестве примера можно взять идею М. Фуко об эндемии: если ранее эпидемии рассматривались в качестве чего-то смертельного, то в современности эпидемия рассматривается как эндемия - то, что можно изучать, контролировать, регулировать, заниматься профилактикой [4]. Одновременно с этим формируются правила в форме нормативных актов и рекомендаций со стороны международных организаций здравоохранения, с помощью которых осуществляется контроль над населением целых стран и континентов. Например, описывая идею Большого Другого и символического порядка, М. Фуко сказал бы, что существуют рекомендательные характеристики (со стороны Всемирной организации здравоохранении или же отечественного Роспотребнадзора), через которые осуществляются властные полномочия, цель которых - регламентация поведения человека на всей Земле. Таким образом, политические и правовые институты используют механизмы привлекательного образца, который становится желательным для исполнения всеми людьми. При этом политико-правовые институты переходят из области принуждения в область рекомендаций, к примеру, со стороны медицинских организаций.

Однако здесь также используются такой тип рассматриваемых институтов, который оказывается свойственным и для традиционного общества: «право меча» становится одним из центральных методов регуляции общественных отношений. Суть этого инструмента социального контроля состоит в том, что суверен обладает возможностью заставить умереть или позволить жить. Будучи субъектом подчинения, индивид теряет самостоятельность собственной телесности, которая переходит в подчинение суверена. Более того, право меча, как показывает Д.В. Попов, «дополняют учреждения образования и здравоохранения, пенитенциарная система нового типа, ярмарки, цирки, кинематограф и несколько позже гипермаркеты, Дисней- ленды и социальные сети» [3, 92]. В результате в психологии человека закрепляется привлекательный образ, а правовые институты трансформируются из области социальных в область биологических и даже некроинститутов, поскольку суверен позволяет человеку не только жить, но и умереть привлекательным образом. Теперь смерть желаема людьми, из нее производят шоу, продавая право на расставание с жизнью в интересах властных акторов.

Совершенно иной подход к современной трансформации сущности политико-правовых институтов реализуется в концепции социальных практик М. де Серто. Этот мыслитель использует образ высотных зданий для описания определенных интеллектуальных установок, детерминирующих принципы построения общества как системы. Девизом формирующегося институционального устройства становится тезис о том, что «на высоте невозможно быть в подавленном состоянии», поскольку именно такое положение определяет разницу в миропонимании «верхов» и «низов». Подавленные низы не способны осознать и увидеть всю полноту реализованных институциональных преобразований, «верхи» же пользуются этим, буквально опираясь на ограниченные потребности «низов» в целях реализации интересующих их трендов.

Центральной у де Серто становится мысль о темпоральности принципов построения общественного и городского пространства. Так, вместо традиционной повседневности, основанной на географическом или геометрическом пространствах (основание которых составляют визуальные, паноптические и теоретические конструкции), появляется кочевая повседневность, фундированная метафоричностью городской жизни. Общеизвестно, что традиционное понимание пространства выражается в форме правильно сформированную структуру, поскольку в ее рамках город трактуется как универсальный автономный субъект, в котором все построено на принципах рациональности, в то время как нерациональное (безумие, преступность, болезнь и смерть) отбрасывается и маркирутеся как «бесполезное» [6]. Следовательно, практическая реализация и функционирование политико-правовых институтов в рамках данного подхода происходит на основании линейной причинно-следственной логики.

Изменение базовых мировоззренческих установок общества влечет за собой трансформацию пространственной организации политико-правовых институциональных структуры, вследствие чего трансформируются и сами способы государственного управления. Содержание властных практик и их реализация определяются интересами населения, которые стремятся обрести комфорт благодаря различным конфигурациям своей жизни. Как утверждает автор рассматриваемой концепции, общество, понимаемое как множество практик, позволяет каждому отдельному индивиду реализовать 
конкретные возможности и определить способ(ы) совершения конкретных действий. Именно в связи с этим возникает дискретность социального и политико-правового пространств: одни события теряют актуальность, другие восходят на вершину значимости. При этом М. де Серто указывает на существование в городе множества разнообразных призраков, одним из которых является «национальное наследие». Французский мыслитель считает, что определенные властные практики в конгруэнтны принципам институционального строительства, поскольку имеют своим основанием нормативно-правовые акты прошлого. Но де Серто отмечает их неэффективность, отождествляя их с архаичными способами регламентации социального порядка, которые неадекватны возникающим вызовам Постсовременности [7]. Здесь сталкиваются две тенденции, одна из которых состоит в стремлении постоянных инноваций, вторая же направлена на сохранение традиционных ценностей.

Центральным моментом становится постоянное обновление идейного содержания, отражающего принципы построения и организации всего социального пространства и, как следствие, системы политико-политических институтов. В постсовременном мире пространство организуется главным образом на основании «устной речи» и «пешеходных прогулок», что выражает определенным образом внутренний мир человека. Раз так, значит, по утверждению М. де Серто, возможно столкновение между персональными и социальными формами миропонимания, заключенного в способах организации городского пространства. «Легендарные» объекты крайне скептически относится к нововведениям, которые не чтут устоявшихся традиций, позволяющих бороться с внешним принуждением, в том числе со стороны властных структур и социальных идей.

В свою очередь сторонники модернизации заявляют о необходимости постоянного обновления облика города, влекущего за собой постоянные трансформации всех форм и способов мышления. В результате возникают новые пути реализации властных отношений, которые М. де Серто образно определяет в качестве «терапевтических инструкций». Власть медикализируется, становясь все более и более «ухаживающей» за подчиненными: акторы берут на себя ответственность за здоровье социального тела, добиваясь реализации «правильных», т.е. соответствующих рекомендациям, социальных практик. В качестве примера французский философ утверждает, что в случае возникновения кризисных явлений зданиям, способным сопротивляться времени, придается тот статус, в котором в частности отказывают пожилым людям. Таким образом, реализуется манипулятивный потенциал политико-правовых институтов по отношении ко всей социальной действительности, в которой ценность необходимых форм социально приемлемого поведения признается исходя из контекстуальных реалий.

Рассматриваемые нами институты прекращают использовать принудительную силу в буквальном смысле этого слова, теперь переходят к применению методологии повседневных практик, в которой критерий правильности определяется скорее ситуативно, напрямую завися не от всей сложной внешней конъюнктуры, но от восприятия конкретного элемента реальности или целого института [5]. Именно подобная точка зрения определяет критерии «нормативности» и «правильности» поведения индивидов и, как следствие, способы оценки его действий со стороны властных акторов и структур. В таком прочтении власть детерминирована набором самых разнообразных практик, что отныне не позволяет однозначно установить какой-либо единый центр, следовательно, это затрудняет определение локации политико-правовых институтов - и это придает их присутствию трансграничный характер.

В целом же отмечаем, что политико-правовые институты в реалиях Постсовременности переходят из области фундаментальных субъектов в сферу повседневности, а основными причины этих трансформаций можно представить двумя большими группами:

- существенная минимизация ресурсов, используемых в процессах реализации властных полномочий, поэтому отныне для обеспечения функционирования органов законодательной, исполнительной и судебной властей не требуется прежних, прежде всего финансовых, огромных затрат;

- большее доверие со стороны подчиненных. Люди, с которыми индивиды сталкиваются в повседневности, оказываются гораздо ближе, нежели виртуальные политические субъекты и институты. Закономерно, что они способны глубже понять их интересы и потребности.

Таким образом, переход власти из области конкретных властных структур в повседневность позволяет добиться не только удешевления реализации политических технологий, но также и достигнуть более высокого исполнения решений, принимаемых политико-правовыми институтами.

\section{ЛИТЕРАТУРА}

1. Желнин А.И. Биополитика и биополитическая экономия: сущность концептов // Вестник Пермского университета. Философия. Психология. Социология. -2019 . - № 3. - C. 320-330. 
2. Попов Д.В. Амбивалентность биополитики в современном мире // Вестник Омского государственного педагогического университета. Гуманитарные исследования. - 2018. - № 4 (21). - С. 35-39.

3. Попов Д.В. Кризис реципрокности: трансформация биополитики в некрополитику // Философия права. - 2019. - № 1 (88). - С. 91-99.

4. Русаков С.С. Трехуровневая концепция политической власти М. Фуко // Человек. Сообщество. Управление. - 2016. - Т. 17. - №1. - С. 114-126.

5. де Серто М. Общее место: обыденный язык [Электронный ресурс]. - Режим доступа: https://magazines.gorky.media/nz/2007/4/obshhee-mesto-obydennyjyazyk.html (Дата обращения: 10.06.2020)

6. де Серто М., Космарский А. По городу пешком // Социологическое обозрение. - 2008. - Т. 7. - № 2. - С. 24-38.

7. де Серто М. Призраки в городе [Электронный ресурс]. - Режим доступа: https://magazines.gorky.media/nz/2010/2/prizraki-v-gorode.html (Дата 0бращения: 10.06.2020)

8. Фантеева 0.В. 0 категории «Другой» в структурном психоанализе // Вестник Томского государственного университета. - 2007. - № 302. - С. 58-61.

9. Фуко М. Надзирать и наказывать. Рождение тюрьмы. - М.: «Ad Marginem», 1999. - 480 c.

(c) Равочкин Никита Николаевич (nickravochkin@mail.ru).

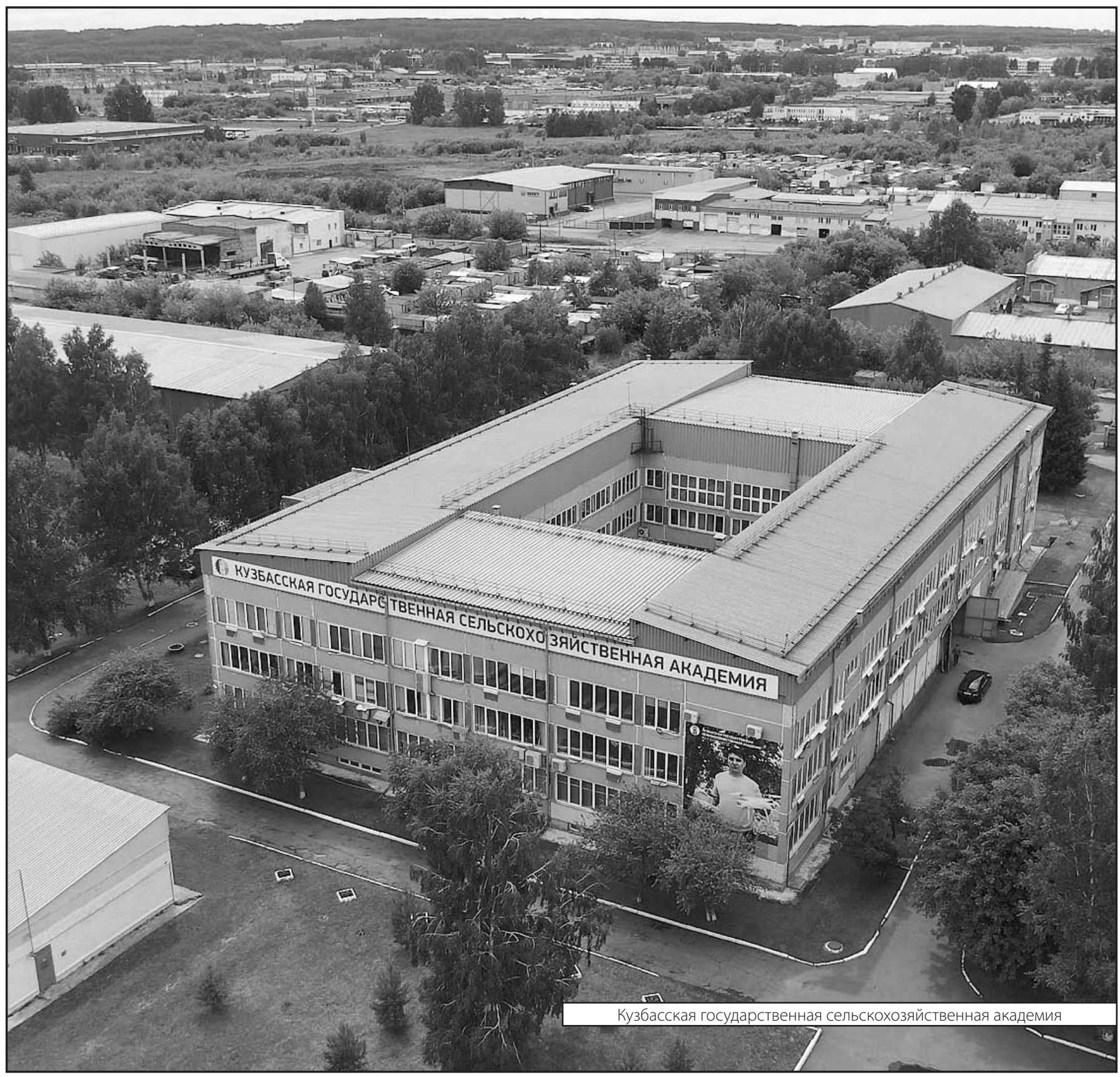

